\title{
Competition of PTB with TIA proteins for binding to a U-rich cis-element determines tissue-specific splicing of the myosin phosphatase targeting subunit 1
}

\author{
SUPRIYA SHUKLA, ${ }^{1}$ FABIENNE DEL GATTO-KONCZAK, ${ }^{3}$ RICHARD BREATHNACH, ${ }^{3}$ and \\ STEVEN A. FISHER ${ }^{1,2}$ \\ ${ }^{1}$ Departments of Medicine (Cardiology) and ${ }^{2}$ Physiology and Biophysics, Case Western Reserve University School of Medicine, \\ Cleveland, Ohio 44106, USA \\ ${ }^{3}$ INSERM U463, Institute de Biologie-CHR, 44093 nantes Cedex 1, France
}

\begin{abstract}
A considerable amount of smooth muscle phenotypic diversity is generated by tissue-specific and developmentally regulated splicing of alternative exons. The control mechanisms are unknown. We are using a myosin phosphatase targeting subunit-1 (MYPT1) alternative exon as a model to investigate this question. In the present study, we show that the RNA binding proteins TIA and PTB function as antagonistic enhancers and suppressors of splicing of the alternative exon, respectively. Each functions through a single U-rich element, containing two UCUU motifs, just downstream of the alternative exon $5^{\prime}$ splice site. Tissuespecific down-regulation of TIA protein in the perinatal period allows PTB to bind to the U-rich element and suppress splicing of the alternative exon as the visceral smooth muscle acquires the fast-phasic smooth muscle contractile phenotype. This provides a novel role for PTB in the tissue-specific regulation of splicing of alternative exons during the generation of smooth muscle phenotypic diversity.
\end{abstract}

Keywords: smooth muscle; phenotype; alternative splicing; myosin phosphatase

\section{INTRODUCTION}

Smooth muscle phenotypic diversity is generated by tissuespecific and developmentally regulated gene expression (Sobue et al. 1999). Phenotypic diversity may be generated by the transcription of related genes within a gene family or by alternative splicing of exons from transcripts generated from a single gene. The recent completion of the sequencing of a number of genomes has found that the number of genes in advanced organisms is significantly lower than estimated. At the same time, it has become evident that the processing of transcripts by alternative splicing of exons plays a substantial role in generation of phenotypic diversity. It is estimated that $60 \%-70 \%$ of all genes undergo alternative splicing of exons as a way to generate protein diversity (Black 2000; Modrek and Lee 2002), and in one particularly robust example, the fly DSCAM gene can potentially give rise to 38,000 different transcripts by competitive splicing of 95 alternative exons (Schmucker et al. 2000).

Reprint requests to: Steven A. Fisher, Department of Medicine (Cardiology), Case Western Reserve University School of Medicine, BRB 422, 2109 Adelbert Rd., Cleveland, OH 44106-4958, USA; e-mail: saf9@po.cwru.edu; fax: (216) 368-0507.

Article published online ahead of print. Article and publication date are at http://www.rnajournal.org/cgi/doi/10.1261/rna.7176605.
In smooth muscle, isoforms of a number of key contractile proteins are generated by alternative splicing of exons, including myosin heavy (Babij and Periasamy 1989; Kelley et al. 1993) and light chains (Nabeshima et al. 1987; Helper et al. 1988), myosin phosphatase (MP) (Shimizu et al. 1994; Johnson et al. 1997; Dirksen et al. 2000), tropomyosin (Wieczorek et al. 1988), caldesmon (Ueki et al. 1987), calponin (Samaha et al. 1996), and others (for review, see Sobue et al. 1999). The tissue-specific expression of these splice-variant isoforms in fast-phasic versus slow-tonic contractile smooth muscle phenotypes (Somlyo and Somlyo 1968) are thought to determine organ function in development and disease (for review, see Owens et al. 2004). We have identified splice variant isoform switching during smooth muscle phenotypic specification in avians and mammals in the embryonic and neonatal periods. This coincides with changes in smooth muscle function in the transition from fetal to adult physiology of the visceral and vascular systems (Dirksen et al. 2000; Ogut and Brozovich 2000; Khatri et al. 2001; Payne et al. 2005). We are now focused on the myosin phosphatase targeting subunit 1 (MYPT1) alternative exons as a model to identify control mechanisms for developmental specification of smooth muscle phenotypes. MP is the primary effector of smooth 
muscle relaxation and MYPT1 is a key target of signals that regulate smooth muscle tone (for review, see Ito et al. 2004). The regulated expression of MP subunits has been proposed as a key determinant of the diversity in smooth muscle contractile properties and in signaling responses in development and disease (Khatri et al. 2001; Payne et al. 2004).

Isoforms of MYPT1 in both birds and mammals are generated by the cassette type alternative splicing of exons in central and $3^{\prime}$ portions of the transcript (Fig.1A; Shimizu et al. 1994; Johnson et al. 1997; Dirksen et al. 2000). We have focused on the avian MYPT1 central 123-nucleotide (nt) alternative exon (MYPT1 exon 12) as a model to understand control mechanisms for the tissue-specific and developmental regulation of alternative exon splicing in smooth muscle phenotypic specification. Around the time of hatching, there is a complete switch in the splicing of this exon from exon inclusion to exon skipping in the chicken gizzard smooth muscle tissue (Dirksen et al. 2000). This switch in splicing is part of a generalized change in the program of gene expression, indicating a switch from the slow-tonic to the fast-phasic smooth muscle phenotype, and is concordant with increases in the rates of muscle contraction and relaxation (Dirksen et al. 2000; Ogut and Brozovich 2000). The specificity of the isoform switching as part of the developmental specification of the fast-phasic smooth muscle phenotype is evident by the absence of isoform switching in the developing aortic smooth muscle, which is always MYPT1 central alternative exon-included/ slow phenotype. In culture, smooth muscle cells (SMCs) express the MYPT1 exon 12-included/slow-tonic isoforms indicative of the embryonic phenotype (Fisher et al. 1997; Dirksen et al. 2000).

In a previous study (Dirksen et al. 2003), we used mutation and deletion analysis of a MYPT1 mini-gene to identify both intronic and exonic cis-regulatory enhancers and suppressors of MYPT1 exon 12 splicing (Fig. 1B,C). We subsequently focused on a U-rich regulatory element (IE1) just downstream of the $5^{\prime}$ splice site. By using cotransfections and RNA-protein binding assays, we identified TIA proteins (TIA-1 and TIAR) as trans-activators of chicken MYPT1 exon 12 splicing functioning through the intronic U-rich enhancer (IE1) (Shukla et al. 2004). TIA-1 and TIAR are $\sim 42-k D$ RNA binding proteins (Tian et al. 1991) that regulate a number of aspects of RNA processing, including activation of splicing of alternative exons by binding to Urich sequences and recruiting U1snRNP to the $5^{\prime}$ splice site (Forch et al. 2000; Gatto-Konczak et al. 2000). Other proteins that enhance or suppress alternative exon splicing in trans have been identified (for review, see Ladd and Cooper 2002). A few studies have identified cis-elements and transacting factors that may regulate alternative exon splicing during phenotypic switching between smooth and nonmuscle phenotypes (Gooding et al. 1998; Gromak et al. 2003a). However the factors that control switching of alternative
A

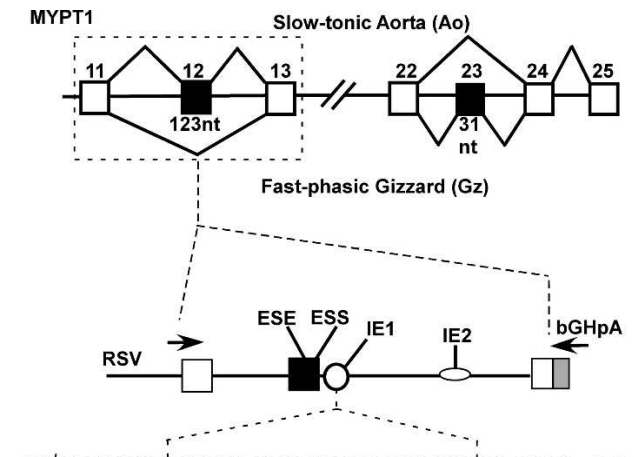

C agGuguggéauUUUCUCUUGUCUUUUUUUUGCUC IE1 AG/GUGUGGGA GCUC dellE1 AGGUGUGGGAUUUCCCCCCCGCCCCUUUUUGGCUC Cmut1+2IE1 AGGUGUGGGaUUUUCUCUUGCCCGUUUUUGCUC Cmut21E1

FIGURE 1. (A) Schematic representation of chicken myosin phosphatase targeting subunit 1 (MYPT1) central and $3^{\prime}$ alternative exon splicing. Exons are depicted as boxes and alternative exons as filled boxes. The number above the exon refers to the position in the MYPT1 gene; below the exon, to the size in nucleotide (nt). Exon 25 is the terminal exon in this gene. The pattern of exon splicing in the slowtonic phenotype aorta versus fast-phasic adult gizzard is also shown. (B) Diagram of MYPT1 mini-gene expression construct used in these studies. The Rous sarcoma virus promoter (RSV) drives transcription of a MYPT1 mini-gene containing exons 11-13 and intervening sequence, fused to the bovine growth hormone polyadenylation signal (grey box) in the pRcRSV plasmid (Invitrogen). Arrows indicate approximate locations of the oligonucleotides that were used in RTPCR in this study. Locations of previously identified cis-enhancers and suppresser of exon splicing are indicated. Diagrams in $A$ and $B$ are not to scale. $(C)$ Sequence of the U-rich intronic enhancer (IE1) and previously characterized deletions (delIE1) and mutations of both (Cmut1+2IE1) or only a single (Cmut2IE1) UCUU motif. The Urich sequence is boldface type, and mutated nucleotides are boxed. The UCUU motifs are underlined. A vertical line in the sequence represents the alternative exon-intron boundary.

exon splicing during developmental smooth muscle phenotypic specification are completely unknown.

The U-rich enhancer of MYPT1 exon 12 that we previously identified also contains two UCUU motifs, consensus binding sites for PTB (polypyrimidine tract binding protein) (Perez et al. 1997). PTB is a ubiquitous splicing repressor (for review, see Valcarcel and Gebauer 1997; Wagner and Garcia-Blanco 2001). We hypothesized that dynamic antagonism between the enhancer TIA and the potential suppressor PTB at the IE1 could regulate the MYPT1 exon 12 splicing. It was less clear how competition between PTB and TIA could mediate the tissue-specific developmental switch to MYPT1 exon 12 skipping that occurs during the specification of the gizzard fast-phasic smooth muscle phenotype around the time of hatching. In this study we show that TIA expression is specifically downregulated in the gizzard smooth muscle at the time of hatching, while the expression of PTB is maintained. The endogenous PTB only binds to the U-rich IE1 after TIA has been down-regulated either in normal development or after 
gene inactivation. Furthermore, loss-of-function studies reveal that PTB suppresses MYPT1 exon 12 splicing in the adult gizzard smooth muscle, in which endogenous TIA is down-regulated, but not in SMCs in which TIA and PTB are coexpressed. These data provide support for a novel model for the role of PTB in the regulated splicing of an alternative exon in developmental smooth muscle phenotypic specification.

\section{RESULTS}

\section{Change in ratio of PTB to TIA proteins during smooth muscle phenotypic specification}

We first examined the expression of PTB and TIA proteins during the developmental period of smooth muscle phenotypic specification. Nuclear extracts (NEs) were prepared from gizzard and aortic smooth muscle tissues, and the abundance of these splicing factors was examined by Western blotting. In NEs from ED15 and ED19 gizzard, TIA-1 was detected as a singlet and TIAR as a doublet at $\sim 42 \mathrm{kD}$ (Fig. 2A, lanes 1,2). There was a sharp decline in the abundance of TIA in the gizzard NEs after hatching (which occurs at approximately ED21) (Fig. 2A, lanes 3,4), consistent with our previous study (Shukla et al. 2004). In contrast, there was no change in the abundance of PTB, which appeared as a doublet migrating at $\sim 60 \mathrm{kD}$ (Fig. $2 \mathrm{~A}$, lanes $1-4)$. This change in the ratio of TIA to PTB closely parallels the switch from MYPT1 exon 12 inclusion to exon skipping around the time of hatching (Dirksen et al. 2000). The change is tissue specific as no change in TIAto-PTB ratios was observed during aortic development (slow-tonic smooth muscle phenotype) (Fig. 2A, lanes 5,6 ), in which the splicing of the MYPT1 (and other transcripts) is also invariant. We next examined PTB-to-TIA ratios in the developing rat portal vein $(\mathrm{PV})$ to determine if the change in the relative abundance of TIA to PTB is more generally true in smooth muscle phenotypic specification. The splicing of MYPT1 and other transcripts switches between postnatal days 3-12 of rat PV development as it acquires the phasic-fast smooth muscle phenotype (Payne et al. 2005). This switching is analogous to that of the chicken gizzard smooth muscle although it occurs slightly later in development. Similar to what occurs in the chicken gizzard, TIAR (Fig. 2B) and TIA-1 (data not shown) proteins are significantly down-regulated in the transition from the D3 neonatal (lane 1) to adult (lane 2) PV. Nuclear PTB abundance is up-regulated (lanes 1,2 ) in this same period, resulting in a significant change in the TIA-to-PTB ratios. As in the chicken, there is no change in the relative abundance of TIA to PTB in rat aorta development (Fig. 2B, lanes 3,4 ). The nuclear protein hnRNP Al served as an additional internal control and was invariant between samples (Fig. 2B).

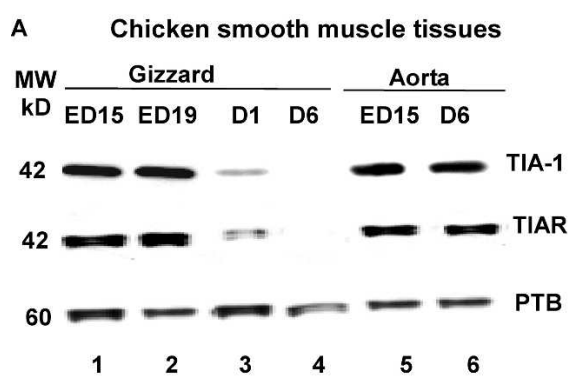

B
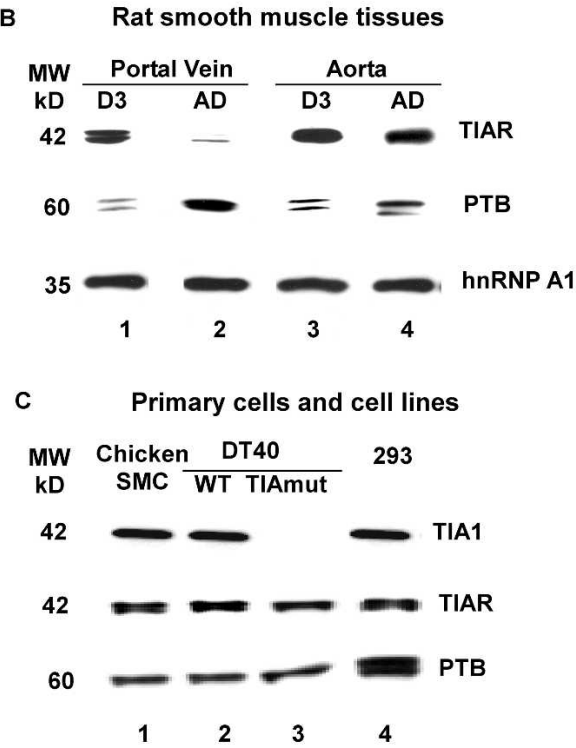

FIGURE 2. PTB expression is maintained while TIA proteins are specifically down-regulated in the development of the fast-phasic smooth muscle phenotype (chicken gizzard and rat portal vein). Ten micrograms of protein from nuclear extracts from $(A)$ chicken smooth muscle tissues, $(B)$ rat smooth muscle tissues, and $(C)$ cultured cells were analyzed for the expression of PTB and TIA. In the 293 cell line in $C, 2.5 \mu \mathrm{g}$ of protein was used. Proteins were separated on $4 \%-12 \%$ NuPAGE Novex bis-tris gels and analyzed by Western blotting, as described in the Methods, by using anti-TIA-1 ML29, anti-TIAR 6E3, anti-PTB DH7, or anti hnRNP A1 4B10 as an internal control. The gizzard and portal vein were used as they are prototypic fastphasic smooth muscle tissues. Developmental time points were selected to precede and follow the switch in alternative exon splicing and the transition from the slow to the fast contractile phenotype. The aorta is shown for comparison as it is always of the slow-tonic phenotype, and there is not switching in the splicing of the alternative exon. TIA $(42 \mathrm{kD})$ and PTB $(60 \mathrm{kD})$ proteins were not detected in the cytosolic fractions of these samples (data not shown). Approximate size of each band in kiloDaltons is indicated. PTB and TIAR are each detected as doublets in all samples. ED indicates embryonic day; D, post-natal day; SMC, primary cultures of gizzard smooth muscle cells; DT40, the avian lymphoid cell line; and DT40 TIAmut, a subline in which three of the four TIA alleles were inactivated by homologous recombination.

We also examined TIA and PTB abundance in cultured SMCs and nonmuscle cell lines. TIA and PTB proteins are coexpressed in cultured gizzard SMCs (Fig. 2C, lane 1) and aortic SMCs (data not shown) at ratios similar to that observed for the tonic-slow smooth muscle tissues in vivo 
(Fig. 2A). We have previously used targeted inactivation of TIA alleles in the chicken lymphoid DT40 cell line (TIA-1 ${ }^{-1}$ ${ }^{-}$TIAR $^{+/-}$; DT40 TIAmut) (Buerstedde et al. 1990; Le Guiner et al. 2003) to study the role of TIA in MYPT1 splicing (Shukla et al. 2004). In the wild-type DT40 cell line, the ratio of TIA to PTB (Fig. 2C, lane 2) is similar to that of the slow-tonic SMCs/tissues. The DT40 TIAmut cells (Fig. 2C, lane 3) show the expected reduction in TIA with no effect on the abundance of PTB. We also examined expression of TIA versus PTB in two mammalian cell lines. In the human embryonic kidney 293 cell line (Graham et al. 1977), PTB and TIA were coexpressed, but in contrast to the cultured avian cells and the rat tonic smooth muscle tissues, PTB was more abundant than was TIA (Fig. 2C, lane 4). Both PTB and TIA proteins were more abundant in the 293 NEs than in the other rat and chicken samples analyzed (note that the amount of 293 nuclear protein loaded onto the gel in Fig. 2 was reduced by one-fourth compared with the other samples). The mouse embryonic aortic SMC-derived A7r5 cell line (Kimes and Brandt 1976) also coexpressed TIA and PTB in a pattern similar to that in 293 cells (data not shown).

\section{PTB is a repressor of splicing of MYPT1 exon 12}

We next sought to determine the role of PTB in relation to TIA in regulated splicing of the MYPT1 exon 12 . We transfected chicken SMCs with $0.05 \mu \mathrm{g}$ wild-type MYPT1 minigene expression vector (depicted in Fig. 1B) with increasing amounts of PTB expression plasmid (Fig. 3A): $0.05 \mu \mathrm{g}$ (lane 2), $0.25 \mu \mathrm{g}$ (lane 3), and $0.5 \mu \mathrm{g}$ (lane 4). The wild-type MYPT1 mini-gene transcript is processed to yield predominately exon inclusion ( $10 \pm 2 \%$ exon-excluded product) as previously reported (Dirksen et al. 2003; Shukla et al. 2004). A significant shift to exon skipping was observed with increasing amounts of the PTB expression plasmid. This contrasts with the effect of cotransfection of TIA-1 expression vectors that results in a shift in the opposite direction to exon inclusion (Shukla et al. 2004).

To determine if the effect of PTB on MYPT1 splicing is mediated via the IE1 element, we examined the effect of cotransfection of PTB expression vectors with the MYPT1 mini-gene construct in which the IE1 was mutated or deleted (Fig. 1C). Deletion of the IE1 caused a large shift to exon skipping ( $80 \pm 5 \%$ exon-excluded) (Fig. 3B, lane 1 ), as we previously reported (Dirksen et al. 2003). Mutation of both UCUU motifs to CCCC has the same effect (Cmut1+2IE1) (Dirksen et al. 2003). In each instance alternative exon splicing was unresponsive to cotransfection with the PTB expression plasmid $(0.5 \mu \mathrm{g}$ PTB: Fig. 3B, lane 2; Cmut1+2IE1: data not shown), indicating that the IE1 was required for PTB to regulate splicing of MYPT1. Mutation of one of the two UCUU motifs (Cmut2IE1), partially disables the TIA-dependent IE1 (Shukla et al. $2004)$ and causes a shift to exon skipping (40 $\pm 5 \%$ exon-

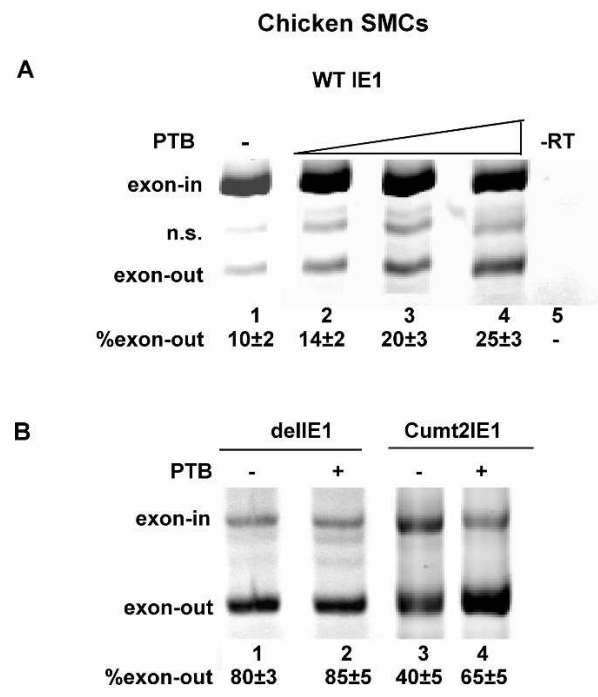

FIGURE 3. PTB represses MYPT1 exon 12 splicing in an IE1 dependent manner. A PTB expression vector $(0.05 \mu \mathrm{g}, 0.1 \mu \mathrm{g}$, and $0.5 \mu \mathrm{g})$ was cotransfected with $0.05 \mu \mathrm{g}$ of $(A)$ wild-type or $(B)$ delIE1 or Cmut2IE1 MYPT1 mini-gene plasmids into cultured chicken SMCs in 24 well plates. In $B$ the results of the highest dose $(0.5 \mu \mathrm{g})$ of PTB expression plasmid cotransfected with delIE1 or Cmut2IE1 are shown. The total amount of plasmid DNA was kept constant in each transfection by including Puc19 plasmid DNA. RNA was harvested $24 \mathrm{~h}$ later, and ratios of MYPT1 exon-included to exon-excluded mini gene transcript were determined by RT-PCR (Fig. 1B). RT-PCR products were separated by $8 \%$ PAGE and detected with a Cy5 fluorescent label (IDT) present on the sense oligonucleotide. The fluorescent signals of the exon-included and exon-excluded products were quantified with a Storm 860 Imager (Amersham Biosciences ImageQuaNT software). In this and subsequent figures, a picture of a representative gel is shown, below which is the quantification from at least three independent transfections. Data groups were compared by one-way ANOVA and Student's $t$-test using Prism version 4.0. $P<0.05$ was considered significant. Data are shown as the mean \pm SD of the percentage of exon-out products (exon-out/total). The exon-included (407-bp) and exon-out (284-bp) RT-PCR products are labeled. n.s. indicates nonspecific RT-PCR products; -RT, control reactions in which RT enzyme was omitted. Negative controls were run for each reaction and resulted in no products; only a single negative control reaction is shown. For explanation of plasmid constructs, see Figure 1.

excluded, lane 3). Cotransfection with the PTB expression vector further represses the splicing of the alternative exon (65 $\pm 5 \%$ exon-excluded, lane 4, $0.5 \mu \mathrm{g}$ PTB), indicating that PTB can suppress splicing with the presence of a single UCUU element in the context of this U-rich sequence. Thus, PTB can function to suppress splicing of the MYPT1 alternative exon through the IE1, the same ciselement that enhances splicing of the exon through a TIAdependent mechanism (Shukla et al. 2004).

\section{PTB binds to IE1 only after TIA proteins are down-regulated}

PTB and TIA are coexpressed in the embryonic gizzard smooth muscle, all aortic smooth muscle, and cultured SMCs. In gain-of-function studies, PTB and TIA have 
antagonistic effects on MYPT1 exon 12 splicing functioning through the IE1. We thus wondered how it could be that these cell types almost exclusively splice the alternative exon. We performed RNA-protein binding assays (Fig. 4) to determine if competition between TIA and PTB in regulating splicing of MYPT1 exon 12 is a function of competition for binding to the IE1. RNA-protein binding reactions were performed with a biotinylated 19-nt IE1

\section{A IE1 :UUUUcucuUgucuUUUUUU}

Control (C) :GAAGGUCCUACAUCCUUAAACACAAGUUA

\section{Chicken SM tissues}
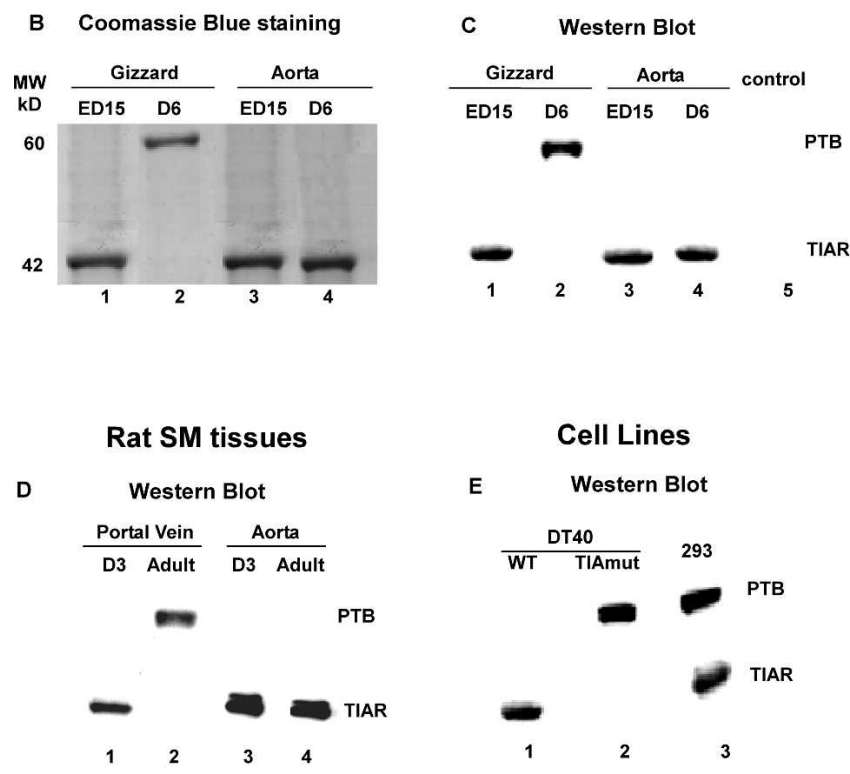

FIGURE 4. PTB only binds to the IE1 when TIA is down-regulated. Biotinylated RNA oligonucleotides containing $(A)$ the 19-nt wild-type IE1 sequence or a control RNA derived from a different region of the MYPT1 gene were reacted with nuclear extracts from $(B, C)$ chicken smooth muscle tissues, $(D)$ rat smooth muscle tissues, and $(E)$ cultured cells. RNA-protein complexes were precipitated with streptavidin magnasphere beads and bound proteins eluted as described in the Methods. Proteins were analyzed by $(B)$ Coomassie blue staining of $4 \%-12 \%$ NuPAGE Novex bis-tris gels and $(C-E)$ Western blotting with anti-TIAR 6E3, anti TIA-1 ML29 (data not shown), and anti-PTB antibody DH7. Proteins bound to the control RNA ( $C$, lane 5; data not shown), and the final wash through of each reaction was collected and examined as a further control for specific binding of proteins to the RNA-beads complex (data not shown). Nuclear extracts were also mixed with streptavidin beads alone with no RNA as a control for nonspecific binding (data not shown). Control reactions were performed for each sample, and no PTB or TIA binding was detected; only a single control binding reaction is shown. Nuclear extracts were analyzed from tissues and cells that are prototypic slow-tonic (all AO samples, ED15 gizzard and D3 portal vein) versus fast-phasic smooth muscle tissues (D6 gizzard, adult portal vein) in which TIA was downregulated (Fig. 2). $(B-D)$ Endogenous PTB binds to the IE1 only in tissues in which endogenous TIA-1 was down-regulated. (E) PTB binds to the IE1 when TIA is down-regulated by gene inactivation in the DT40 cell line (cf. DT40 wild type versus TIAmut). In 293 nuclear extracts where PTB is highly expressed (Fig. 2), both PTB and TIA binding to the IE1 are detected. Abbreviations are as in Figure 2. oligonucleotide sequence or a control oligonucleotide derived from a different part of the MYPT1 gene (Fig. $4 \mathrm{~A})$. Eluted proteins were examined by Coomassie blue staining of gels (Fig. 4B) and Western blotting (Fig. 4C-E) with antibodies against TIA and PTB proteins. In binding reactions using ED15 gizzard NE and ED15 or adult aorta NEs (tonic smooth muscle phenotype, alternative exonincluded), IE1 bound an $\sim 42-\mathrm{kD}$ nuclear protein (Fig. $4 \mathrm{~B}$, lanes $1,3,4$ ) identified as a mixture of TIAR (Fig. $4 \mathrm{C}$, lanes $1,3,4)$ and TIA-1 (not shown) by Western blot. In binding reactions that used NE from D6 gizzard tissue (phasic smooth muscle phenotype, alternative exon-excluded), IE1 bound a nuclear protein migrating at $\sim 60 \mathrm{kD}$ and not at $\sim 42 \mathrm{kD}$ (Fig. 4B, lane 2). Western blotting with anti-PTB DH7 (Grossman et al. 1998) identified the $\sim 60-\mathrm{kD}$ protein as PTB (Fig. 4C, lane 2). Thus, PTB binding to the IE1 was detected only with the NE in which TIA expression was down-regulated (D6 gizzard). The same pattern was observed in rat smooth muscle tissues (Fig. 4D). In binding reactions that used NEs from neonatal rat PV (D3) and aorta tissues from any developmental stage, which display the slow-tonic pattern of alternative exon splicing, TIA binding to the IE1 was observed (Fig. 4D, lanes 1,3,4). In contrast in NE from the adult PV, which displays the fastphasic pattern of alternative exon splicing and TIA is downregulated, PTB binding to the IE1 was detected (Fig. 4D, lane 2). Thus, in both the avian gizzard and rat PVs, PTB binding to the IE1 is detected only after TIA is downregulated as part of the transition to the fast-phasic pattern of alternative exon splicing/muscle phenotype.

There are many differences in the ensemble of gene expression between the slow-tonic and fast-phasic smooth muscle phenotypes (for review, see Sobue et al. 1999). We used gene inactivation to more specifically determine if TIA down-regulation is required for PTB binding to the IE1. We examined TIA and PTB binding in a DT40 cell line in which TIA expression was down-regulated through inactivation of three of four TIA alleles by homologous recombination (DT40 TIAmut) (Le Guiner et al. 2003). In binding reactions using NE from wild-type DT40 cells, TIA but not PTB bound to the IE1 (Fig. 4E, lane 1). In NEs from the DT40TIAmut cell line, PTB bound to the IE1 (Fig. 4E, lane 2). On longer exposures of the Western blot in these experiments, a faint TIAR signal could be observed with DT40 TIAmut NE (data not shown). Thus, PTB binds to the IE1 only when the endogenous TIA is down-regulated either in developmental specification of smooth muscle phenotypes, or through gene inactivation in the DT40 cell line, suggesting that TIA binds to the IE1 with a higher affinity and blocks the binding of PTB in these cell types. In the transformed mammalian 293 cell line, where PTB is highly expressed relative to TIA (Fig. 2C), PTB and TIA both bind to the IE1 (Fig, 4E, lane 3), further supporting a model of competition between TIA and PTB for binding to the IE1. In summary, the competitive binding of PTB and 
TIA proteins to the IE1 correlates well with the tissuespecific splicing of the chicken MYPT1 exon 12.

\section{Endogenous PTB represses splicing of the MYPT1 exon 12 via IE1 in a cell type-specific manner}

We have observed that PTB binds to IE1 in the posthatched D6 gizzard where the exon is skipped, but not in the tonic phenotype smooth muscle (ED15 gizzard) where the exon is included. To test the function of endogenous PTB in these different contexts we used a dominant-negative PTB construct (DNPTB) described in a previous study (Charlet et al. 2002). As an alternative approach, we used RNA interference to knock down PTB expression as previously described (Wagner and Garcia-Blanco 2002). Cotransfection of the MYPT1 mini-gene $(0.05 \mu \mathrm{g})$ (Fig. $5 \mathrm{~A}$, lane 1) with increasing amounts of the DNPTB expression vector $(0.05 \mu \mathrm{g}$, lane $2 ; 0.1 \mu \mathrm{g}$, lane $3 ; 0.5 \mu \mathrm{g}$, lane 4$)$ in cultured SMCs had no effect on the splicing of MYPT1 exon 12. Similarly, knock-down of PTB with siRNA produced the expected decrease in PTB protein levels (Fig. 5C) but had no effect on the splicing of the MYPT1 mini-gene construct in the cultured SMCs (Fig. 5B, lane 2). These data are consistent with the RNA binding data in indicating that MYPT1 exon 12 splicing is not under the control of endogenous PTB in the tonic SMC phenotype.

We next examined if splicing of MYPT1 is under the control of endogenous PTB in the phasic smooth muscle phenotype where PTB binds to the IE1. We used the method that we developed of plasmid DNA injection into the intact gizzard smooth muscle in vivo (Dirksen et al. 2003), as gizzard SMCs in culture revert to the embryonic phenotype in which the alternative exon is not skipped (Dirksen et al. 2000) and TIA proteins are re-expressed (Fig. 2). In contrast to the cultured SMCs, coinjection of wild-type MYPT1 mini-gene $(2.5 \mu \mathrm{g})$ with the DNPTB expression vector $(25 \mu \mathrm{g})$ derepressed splicing of the alternative exon, i.e., caused a shift to exon inclusion. The wildtype MYPT1 mini-gene yields $28 \pm 4 \%$ exon-skipped products as previously reported (Dirksen et al. 2003), while coinjection of DNPTB expression plasmid resulted in $18 \pm 1 \%$ exon skipping (Fig. 5D, lanes 1,2). Coinjection of a TIA expression vector also reduced exon skipping to a level ( $\sim 10 \%$; lane 3$)$ that is observed with the wild-type MYPT1 mini-gene construct in the slow-tonic SMCs. Coinjection of the PTB expression vector shifted MYPT1 minitranscript processing in the opposite direction $(55 \pm 3 \%$ exon-excluded) (Fig. 5D, lane 4). Dose-response relationships were observed for all expression vectors tested (data not shown). These data indicate that splicing of the MYPT1 exon 12 is under the control of endogenous PTB in the fastphasic gizzard SMCs but not in the slow-tonic SMCs. The effects of PTB and TIA to suppress and enhance splicing, respectively, were entirely dependent on the IE1 element. Coinjection into the gizzard of DNPTB, TIA-1, or full-

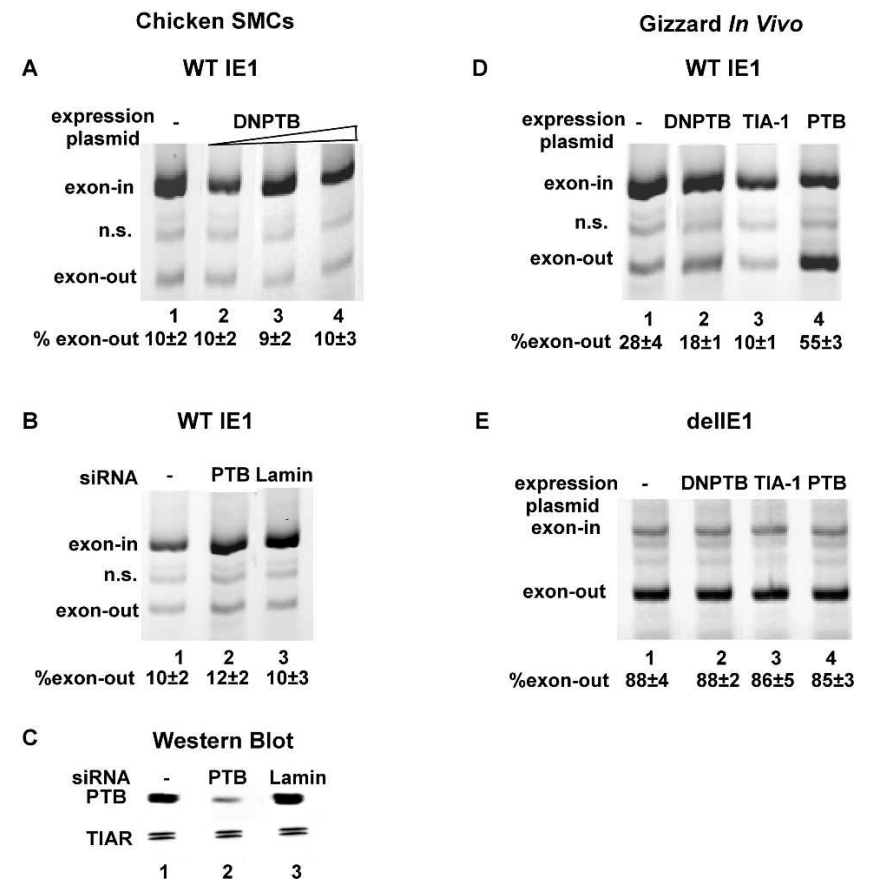

FIGURE 5. Dominant negative PTB relieves repression of MYPT1 exon 12 splicing specifically in phasic smooth muscle. (A) Increasing amounts of a dominant negative PTB expression vector $(0.05 \mu \mathrm{g}, 0.25$ $\mu \mathrm{g}$, and $0.5 \mu \mathrm{g}$ ) was cotransfected with the wild-type MYPT1 minigene plasmid $(0.05 \mu \mathrm{g})$ into cultured chicken SMCs in 24-well plates. (B) PTB was knocked down in cultured chicken SMCs by transfection of siRNA against PTB (as described in the Methods) and cotransfected with the wild-type MYPT1 mini-gene plasmid. siRNA against Lamin functions as a negative control. RNA was harvested, and ratios of MYPT1 exon-included to exon-excluded mini-gene transcript were determined as described in the legend to Figure 3. Neither DNPTB nor siRNA knock-down of PTB had an effect on MYPT1 mini-gene splicing in the cultured SMCs. $(C)$ Western blot analyses of nuclear extracts prepared from control SMCs or SMCs transfected with siRNA against PTB or Lamin. Nuclear extracts were prepared $48 \mathrm{~h}$ after transfection. PTB levels are reduced as a result of siRNA-mediated knock-down. Constant TIAR levels in these samples are shown as control. $(D)$ Wildtype MYPT1 mini-gene plasmid $(2.5 \mu \mathrm{g})$ along with vectors expressing either DNPTB, TIA-1, or PTB was coinjected into 6-d-old chicken gizzard in vivo. RNA was harvested and analyzed for MYPT1 exonincluded to exon-excluded minigene transcript as described in the Methods. DNPTB and TIA-1 each caused a shift to exon inclusion $(P<0.001)$, while expression of PTB caused an opposite shift to exon skipping $(P<0.001)$. The data for the highest amount of each expression construct $(25 \mu \mathrm{g})$ are shown. Dose response studies $(2.5 \mu \mathrm{g}, 12.5$ $\mu \mathrm{g}$, and $25 \mu \mathrm{g}$ ) of each expression vector were performed and showed a dose-response relationship (data not shown). (E) The effects of DNPTB, TIA-1, and PTB are dependent upon the IE1, as there is no effect when the delIE1 (or Cmut1+2 IE1) (data not shown) constructs are coinjected with DNPTB, TIA-1, or PTB expression vectors. Data shown are the mean- \pm SD of at least three independent transfections. -RT controls produced no product (data not shown). Abbreviations and labels are as in Figure 3.

length PTB with delIE1 did not alter the ratio of $\sim 90 \%$ exon-excluded transcripts (Fig. 5E, lanes 2,3,4 respectively).

We next sought a cell culture model where the effects of endogenous PTB could also be tested. We previously 
reported that the MYPT1 mini-gene produces $~ 50 \%$ exonskipped transcripts when transfected into the human embryonic kidney 293 cell line (Shukla et al. 2004), and slightly less ( $\sim 34 \%$ exon-skipped) in the A7r5 embryonic aortic smooth muscle derived cell line (Fig. 6A, lanes 1,4, respectively). We also observed high levels of PTB expression in these cell lines and binding of PTB to the IE1, suggesting that splicing of the MYPT1 mini-transcript may be under the control of PTB in these cells. To test this, these cells were cotransfected with the MYPT1 minigene construct and DNPTB or PTB siRNA for loss-offunction experiments and wild-type PTB expression vectors
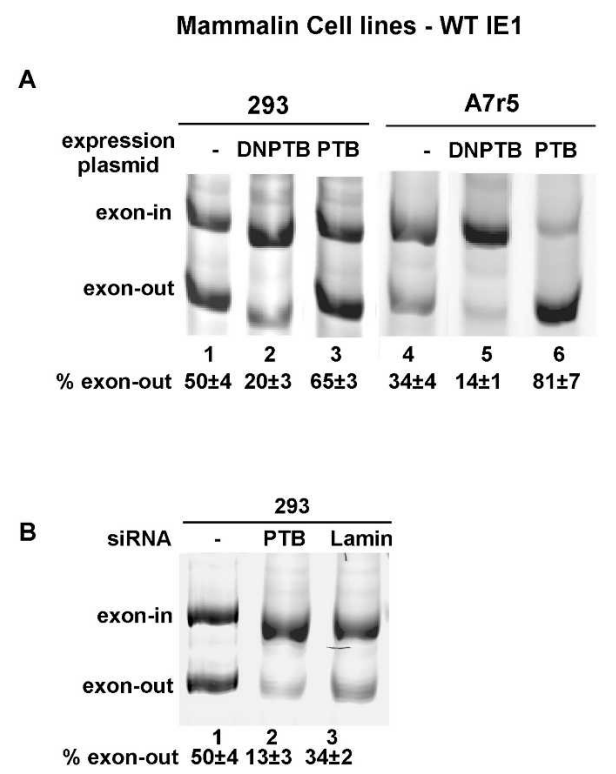

C

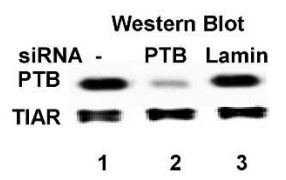

FIGURE 6. PTB regulates MYPT1 exon 12 splicing in 293 and A7R5 mammalian cell lines. (A) Cotransfection of $0.1 \mu \mathrm{g}$ of wild-type MYPT1 mini-gene plasmid with $0.1 \mu \mathrm{g}$ dominant negative PTB (DNPTB) expression vector (lanes 2,5) derepresses splicing of the alternative exon $(P<0.001)$, while cotransfection with $0.1 \mu \mathrm{g}$ PTB expression vector (lanes 3,6) represses splicing of the alternative exon $(P<0.001)$. (B) Knock-down of PTB with siRNA also derepresses splicing of the alternative exon in 293 cells. There was a smaller effect with the control siRNA against Lamin, suggesting a small nonspecific effect secondary to the siRNA method. RNA was harvested, and ratios of MYPT1 exon-in to exon-excluded minigene transcript were determined as described in legend to Figure 3. Data shown are the mean \pm SD of at least three independent transfections. The data for the highest amount of each expression construct are shown. Doseresponse studies $(0.01 \mu \mathrm{g}, 0.05 \mu \mathrm{g}$, and $0.1 \mu \mathrm{g})$ of each expression vector were performed and showed a dose-response relationship (data not shown). (C) Western blot analyses (as described in the Methods) of nuclear extracts prepared from SiRNA transfected 293 cells show reduced levels of PTB as a result of PTB knock-down by siRNA, while the levels of TIAR remain constant. for gain-of-function experiments, as described above. Cotransfection of DNPTB derepressed splicing of the alternative exon, i.e., caused a significant shift to exon inclusion in both cell types (Fig. 6A, lanes 2,5). Interestingly, the magnitude of the effect of DNPTB was greatest in the 293 cells, in which the basal level of exon skipping was higher $(50 \%$ vs. 34\% in A7r5), consistent with a greater influence of PTB in this cell line. Inhibition of PTB by siRNA knock-down (Fig. 6C) had a similar effect in the 293 cell line, with a reduced expression of PTB protein as expected (Fig. 6B, lane 2; A7R5 was not tested). The control siRNA against Lamin also had an effect in these experiments that was much smaller than the knock-down of PTB. Cotransfection of wild-type PTB had the opposite effect, causing a shift to exon skipping in both the 293 and A7r5 cell lines (Fig. 6A, lanes 3,6). As in the prior experiments, the effects of the various PTB manipulations were entirely dependent on the presence of an intact IE1 (data not shown).

\section{DISCUSSION}

There are dramatic changes in the programs of gene expression in the generation of smooth muscle diversity and acquisition of the mature phenotypes. We previously showed switching in the selection of alternative exons in avian gizzard and mammalian PVs in the embryonic and neonatal periods, respectively (Fisher et al. 1997; Dirksen et al. 2000; Khatri et al. 2001; Payne et al. 2005), as they acquire the fast-phasic contractile smooth muscle phenotype. The control mechanisms for these developmental decisions in alternative exon selection in smooth muscle are completely unknown. We had previously shown that alternative splicing of the MYPT1 exon 12 requires a U-rich cis-enhancer near the $5^{\prime}$ splice site (Dirksen et al. 2003) through which TIA proteins activate splicing of the exon in tonic SMCs and nonmuscle cells (Shukla et al. 2004). These studies did not address the mechanism(s) for the tissue-specific switch to exon skipping that occurs in the fast-phasic smooth muscle in the perinatal period. A key observation in the current study is that TIA proteins are specifically down-regulated in the phasic smooth muscle tissues in the late embryonic and neonatal periods, while the ubiquitous suppressor of splicing PTB continues to be expressed. In this study we used gain-of-function and lossof-function studies and RNA-protein binding studies to support a novel model: PTB competes with TIA for binding to the IE1 regulatory element, and the net balance of TIA versus PTB activity in part determines the splicing of a MYPT1 alternative exon during smooth muscle phenotypic specification.

The evidence that competition between TIA and PTB proteins determines splicing of MYPT1 includes gain-of-function studies, in which cotransfection of TIA-1 or PTB expression vectors with the MYPT1 mini-gene results in increased or decreased splicing of the alternative exon, respectively. That 
TIA and PTB are both dependent upon the IE1 for their activities is indicated by the absence of an effect when the 19bp IE1 is mutated or deleted. A prior study showed competition between PTB and TIA in the regulation of splicing of the cystic fibrosis transmembrane conductance rectifier (CFTR) alternative exon 9 (Zuccato et al. 2004). However, in that study the suppressive effect of PTB was independent of the U-rich TIA binding cis-enhancer, and no specific PTB-dependent cissuppressor element was identified. There was also no indication as to how PTB versus TIA might function in a tissuespecific manner. This is the first study to suggest that PTB may suppress splicing through its competition at a TIA-dependent U-rich cis-enhancer element. Other studies have suggested that PTB suppresses splicing by establishing a zone of suppression through binding to multiple regulatory elements both $5^{\prime}$ and $3^{\prime}$ to the alternative exon (for review, see Wagner and GarciaBlanco 2001). This does not appear to be a universal requirement for PTB suppression, as suppression of the IgM M1 and M2 alternative exons also requires only a single PTB regulatory element (Shen et al. 2004).

The gain-of-function studies did not indicate how the endogenous PTB and TIA might function through the IE1 to regulate splicing of the MYPT1. More specifically, TIA and PTB are coexpressed in the embryonic gizzard and all aortic smooth muscle, as well as in the cultured avian smooth muscle and nonmuscle cells, yet there is no skipping of the endogenous MYPT1 exon 12. The initial solution to this question came from RNA-protein binding studies, which showed that only TIA bound to the IE1 in the avian and mammalian tissues/cell types in which TIA and PTB were coexpressed. This was not due to an inability of PTB to bind to the U-rich IE1, which contains two consensus PTB binding motifs (UCUU) (Perez et al. 1997). In NEs from the post-hatched gizzard, and in postnatal mammalian PV, in which endogenous TIA was downregulated, PTB binding to the IE1 was detected. These experiments with the NEs with varying ratios of endogenous TIA versus PTB were supported by the genetic depletion of the endogenous TIA in the DT40 cell line, which also resulted in PTB binding to the IE1. This suggests that the endogenous PTB has a lower affinity for the IE1 than TIA-1 and is out-competed for it. There is still low level TIA expression in the DT40 TIA $^{-/-}$TIAR $^{+/-}$cell line, but now PTB binds IE1 accompanied by a significant shift to exon skipping, supporting a model in which PTB's primary function is to displace the activator TIA when present at limiting concentrations. This aspect of the model has similarities to one proposed for the regulated splicing of the glycine receptor $2 \mathrm{E} 3 \mathrm{~A}$ alternative exon. The paraneoplastic protein Nova binds to a UCAU motif and activates splicing with a 10-fold higher affinity than the binding of the suppressor "brain" isoform of PTB to a nearby regulatory element (Polydorides et al. 2000). (The "brain" isoform of PTB is generated from a different gene than the PTB studied here.) However how these competitor trans-activators and trans- suppressors may function to regulate tissue-specific splicing of the exon in neural tissues was not addressed in the in vitro study.

To test the function of PTB in regulating MYPT1 exon 12 splicing we used loss-of-function studies. Both cotransfection of a DNPTB expression vector and knock-down of PTB by RNA interference resulted in a diminution of exon skipping in specific cell types. The DNPTB reduced exon skipping in the post-hatched gizzard in vivo, in which TIA is down-regulated, PTB binds, and the endogenous exon is skipped. In contrast DNPTB or PTB knock-down had no effect in the cultured avian SMCs, in which PTB does not bind (although it is expressed), TIA does bind, and the endogenous exon is spliced. One peculiarity of the in vivo transient transfection (injection) method is that the exogenous MYPT1 mini-gene derived alternative exon is skipped $27 \%$ of the time. While this is $\sim 2.5$-fold more than in the cultured SMCs (10\% exon skipped), it is less than the endogenous transcript, with close to $100 \%$ exon skipping. We have previously shown that the regulation of splicing of the MYPT1 alternative exon reflects the balance of a number of cis-enhancers and suppressors (Dirksen et al. 2003), consistent with other models of regulated exon splicing. It is possible that the transient transfection titrates out tissuespecific suppressors of exon splicing. Nonetheless, DNPTB suppresses exon skipping in this cell type where PTB binds IE1, but not in the cultured SMCs where PTB does not bind, providing support for the proposed model for tissuespecific regulation of MYPT1 exon 12 splicing. DNPTB does not derepress splicing entirely to the level observed in the tonic SMCs (10\% exon-out). One potential explanation for the partial effect is that the factor binding to the ESS can function to suppress splicing independent of PTB. Consistent with the proposed independence of these two suppressor elements, PTB can still function to suppress MYPT 12 exon splicing when the ESS is mutated (data not shown). This contrasts with the enhancer elements, in which mutation of the exonic splicing enhancer abrogates the ability of TIA to enhance splicing (Shukla et al. 2004).

The data obtained with the mammalian 293 and A7r 5 cell lines also provide support for the model of dynamic antagonism between PTB and TIA at the IE1 regulating splicing of the MYPT1 exon 12. The data obtained with these cell lines cannot be used to support conclusions regarding tissue-specific regulation of splicing, since these cell lines are transformed. PTB expression is markedly up-regulated in neoplastic neural tissues (McCutcheon et al. 2004) and was also very high in the transformed human embryonic kidney 293 cell line (transformed with sheared adenovirus 5 DNA (Graham et al. 1977) compared with mammalian tissue NEs. Interestingly, there was a good correlation in these cell lines among the level of expression of PTB, the degree of exon skipping from transfected mini-gene transcripts, and the magnitude of the effect of DNPTB or PTB knock-down on exon skipping. 
It has been proposed that modest changes in the stoichiometries of general spicing factors, e.g., the SR splicing factors, results in tissue-specific splicing (for review, see Smith and Valcarcel 2000). The results of the current study support a different model in which tightly restricted tissue-specific expression of splicing factors dictates developmental decisions for selection of alternative exons: tissuespecific down-regulation of the splicing enhancer TIA allows for the suppression of splicing of an alternative exon by a ubiquitous suppressor, PTB. This model of dynamic antagonism between the suppressor PTB and a competitive enhancer is similar to what has been proposed for tissue-specific and developmentally regulated splicing of cardiac troponinT (Ladd et al. 2001) and smooth muscle $\alpha$ actinin (nonmuscle vs. smooth muscle) (Gromak et al. 2003a) alternative exons. In these models competition between PTB and the CELF class of splicing trans-activators has been proposed to determine the tissue-specific splicing of the alternative exons. However, there are also important differences between these studies. In the study of the competitive splicing of the smooth muscle versus nonmuscle $\alpha$ actinin alternative exons, it was proposed that the CELF trans-activator binding to CUG motifs displaces the PTB suppressor from nearby UCUU motifs. In our study PTB and TIA compete for the same cis-element in the reverse order, with the enhancer TIA out-competing PTB for binding to the IE1. Another important difference between the studies is that the current study showed changes in endogenous TIA versus PTB binding to the IE1 from tissues in which there was a corresponding switch in splicing of the alternative exon. In the study of the $\alpha$-actinin alternative exons, binding of CELF class versus PTB proteins was determined by addition of exogenous proteins. Unlike the current study, the identified CELF and PTB binding sites had only a very minor role in the regulated splicing of the $\alpha$-actinin alternative exons. Thus, it remains to be determined how competition between PTB and CELF proteins can determine selection of alternative exons during differentiation from a nonmuscle to a smooth muscle phenotype, a process that occurs prior to the smooth muscle phenotypic specification studied here.

A key step in the acquisition of the fast-phasic smooth muscle phenotype appears to be the down-regulation of TIA expression. Our own data, as well as those of others, suggest that TIA proteins are restricted in their expression across tissues while the mRNA are more broadly expressed (Taupin et al. 1995; Beck et al. 1996), suggesting tissuespecific post-transcriptional silencing of expression. It will be of interest to work upstream in this pathway and determine the mechanisms for the tissue-specific silencing of TIA expression. TIA proteins may also regulate and autoregulate mRNA translation (Piecyk et al. 2000), and whether that plays a role in their tissue-specific expression remains to be determined. PTB expression is also complex, with a number of different isoforms and cofactors (Woller- ton et al. 2001; Rahman et al. 2002; Gromak et al. 2003b). While there was no evidence in the current study for the tissue-specific expression of PTB 1 versus 4 splice variant isoforms, we cannot exclude the possibility that regulated expression of other PTB isoforms (e.g., the brain isoform), or binding cofactors, plays a role in the selection or suppression of alternative exons during the generation of smooth muscle phenotypic diversity. At the same time that the MYPT1 exon 12 is switching from exon inclusion to exon skipping, the $3^{\prime}$ alternative exon is being controlled in just the opposite fashion, switching from exon skipping to exon inclusion. It thus is likely that many more tissuerestricted suppressors and enhancers of alternative exon splicing that are required for the generation of smooth muscle phenotypic diversity remain to be discovered.

\section{MATERIALS AND METHODS}

\section{Protein analysis}

Nuclear extracts (NEs) were prepared from embryonic or posthatched gizzard and aorta tissues, neonatal and adult rat PV and aorta tissues, cultured gizzard cells, A7r5 cells (an embryonic rat aortic smooth muscle cells line), or 293 cells as previously described (Shukla et al. 2004). NEs from DT 40 cells were prepared in the Breathnach laboratory as previously described (Lee et al. 1988). Proteins were separated on a $4 \%-12 \%$ gradient NuPAGE Novex bis-tris gels (Invitrogen) and either visualized by Simply blue Coomassie Stain (Invitrogen) or electro-blotted onto a polyvinylidene difluoride membrane (Amersham Biosciences). Membranes were blocked in 5\% nonfat dry milk (w/v) in wash buffer for $1 \mathrm{~h}$ and probed with monoclonal antibodies ML29 against TIA-1, 6E3 against TIAR (Kedersha et al. 1999), DH-7 against PTB (Grossman et al. 1998), and 4 B10 against hnRNPA1 (a gift from Dr. Dreyfuss, University of Pennsylvania). The secondary antibodies were horseradish peroxidase conjugated. Signals were detected by ECL (Amersham Biosciences).

\section{Tissue culture, transfection of plasmid DNA, and RNA interference assay}

Smooth muscle cells (SMCs) were isolated from embryonic chicken gizzards and cultured in Dulbecco's modified Eagle's medium (DMEM)/F-12 media with $10 \%$ heat inactivated fetal bovine serum (HFBS HyClone laboratories) and 1\% sterile-filtered chicken serum (Sigma) as described (Dirksen et al. 2003). 293 cells (Quantum Biotechnology) and A7r5 (Kimes and Brandt 1976) cells were grown in monolayer in DMEM supplemented with $10 \%$ serum (HFBS). Cells were transfected with plasmid DNA by using LipofectAMINE as a carrier by standard methods as described (Dirksen et al. 2003; Shukla et al. 2004). Cells in 24well plates were cotransfected with $0.05-0.1 \mu \mathrm{g}$ of the RcRSV plasmid containing a wild-type or mutant MYPT1 mini-gene (Fig. 1B; Dirksen et al. 2003) and a wild-type (Lou et al. 1999) or a DNPTB construct that lacks RNA binding domains RRM3 and RRM4 of PTB (DNPTB) (Charlet et al. 2002). Dose-response studies were performed with each cotransfected expression vector with ratios of expression vector to mini-gene plasmid ranging 
from 1:10-10:1. Dose-response studies were necessary as we have previously found that the RSV promoter is considerably more potent than is the CMV promoter in avian cells, while the reverse is true in mammalian cells (data not shown). Similar observations have been made by other investigators (Smith et al. 2000). Puc 19 plasmid DNA was included to maintain a constant amount of plasmid DNA in each transfection. Total RNA was isolated 24$48 \mathrm{~h}$ after transfection by using the Absolutely RNA kit (Stratagene) following the manufacturer's protocol.

For RNA interference, cultured avian SMCs or mammalian 293 cells were cotransfected with small interfering RNA (siRNA) synthetic duplex designed for PTB (for description, see Wagner and GarciaBlanco 2002). The PTB target sequence for the siRNA is identical in chicken and rodents (data not shown). Included in the cotransfection was a wild-type or mutant MYPT1 mini-gene and LipofectAmine2000 (Invitrogen), following the procedure described by Elbashir et al. (2002). Briefly, on day 1 , cells were plated in a 24 -well plate, as described above. On day $2,2 \mu \mathrm{L}$ of a $20 \mu \mathrm{M}$ stock of siRNA duplex was mixed with $48 \mu \mathrm{L}$ OPTI-MEM for each well. In a separate tube, $2 \mu \mathrm{L}$ of LipofectAmine2000 (Invitrogen) was added to $48 \mu \mathrm{L}$ of OPTIMEM, mixed gently, and incubated at room temperature for $5 \mathrm{~min}$. The two solutions were combined and incubated for $25 \mathrm{~min}$ before being adding to the cells. Forty-eight hours post-transfection (day 4) cells were transfected with a wild-type or mutant MYPT1 mini-gene as described (Shukla et al. 2004). On day 5, cells were harvested to either isolate RNA for RT-PCR or prepare NE to measure PTB abundance. NEs were also prepared from siRNA duplex transfected cells at three different time points $(24 \mathrm{~h}, 48 \mathrm{~h}$, and $72 \mathrm{~h}$ post-transfection) for Western blot analysis. siRNA duplex for nuclear protein Lamin (a kind gift from Dr. H Lou, Case Western Reserve University, Cleveland, Ohio) was used as control for the RNAi assay.

\section{In vivo gene delivery}

A wild-type or mutant MYPT1 mini-gene plasmid $(2.5 \mu \mathrm{g})$ was coinjected with TIA-1 (Kedersha et al. 2000), or a wild-type PTB (Lou et al. 1999) or DNPTB (Charlet et al. 2002) expression vectors into 6-d-old chicken gizzard in vivo following a method developed in our laboratory (Dirksen et al. 2003). Dose-response studies were performed with each coinjected expression vector as described above. Total RNA was isolated from the injected gizzard muscle (indicated by coinjected Evans blue dye) $24 \mathrm{~h}$ after injections by using an Absolutely RNA kit (Stratagene) following the manufacturer's protocol.

\section{RT-PCR of RNA}

RNA was isolated from transfected and injected samples and analyzed by RT-PCR for the presence of exon-included and exon-skipped MYPT1 mini-gene transcripts as described previously (Shukla et al. 2004). In these reactions a $3^{\prime}$ primer is used that specifically anneals with the bGH polyadenylation sequence present only in the exogenous MYPT1 mini-gene transcript. The RT-PCR products were separated on a $8 \%$ native polyacrylamide gel. Visualization of the RT-PCR products was accomplished by $5^{\prime}$-end labeling the sense PCR oligonucleotide with a Cy5 fluorescent label (IDT). The fluorescent signals of the exon-included and exon-excluded products were quantified with a Storm 860 Imager (Amersham Biosciences) and Amersham Bio- sciences ImageQuaNT software. RT reactions were performed with $0.5-2 \mu \mathrm{g}$ of total RNA from transfected samples or $10 \mu \mathrm{g}$ of total RNA from injected samples and $1 / 5$ to $1 / 115$ of the RT reactions used in the PCR. PCR consisted of 23-27 (transfected) or 30-35 (injected) cycles of amplifications. In these assays negative control reactions were performed in which the AMV RT enzyme was omitted from the RT reaction.

\section{Statistics}

All the data shown in this study represent mean \pm SD from at least three independent transfections or injections of each expression plasmid. Data groups were compared by one-way ANOVA and Student's $t$-test using Prism version 4.0. $P<0.05$ was considered significant.

\section{RNA protein binding assay}

The RNA protein binding assay was carried out as described previously (Shukla et al. 2004). Briefly, binding reactions were performed in $250 \mu \mathrm{L}$ binding buffer consisting of $100 \mathrm{mM}$ HEPES, $10 \mathrm{mM} \mathrm{MgCl} 2,500 \mathrm{mM} \mathrm{KCl}, 50 \%$ Glycerol, $10 \mathrm{mM}$ DTT, $20 \mathrm{mM}$ creatine phosphate, $2 \mathrm{mM}$ ATP, and $2.0 \mu \mathrm{L}$ BSA $(10 \mathrm{mg} / \mathrm{mL}), 10 \mu \mathrm{g}$ t-RNA, $200 \mathrm{pmol}$ biotin-labeled RNA, and 250 $\mu \mathrm{g}$ of NE. After 10 -min incubation at $30^{\circ} \mathrm{C}$, the reaction mixture was added to $400 \mu \mathrm{L}$ Streptavidin Magnesphere particles (Promega), prewashed five times with the binding buffer without $t$ RNA. The reaction mixture was incubated with the prewashed beads for $15 \mathrm{~min}$ at $30^{\circ} \mathrm{C}$ to allow binding of the protein-RNA complex to the beads. The beads-RNA-protein complex was then washed five times with binding buffer. After the final wash, $30 \mu \mathrm{L}$ of $2 \times$ protein sample buffer was added to the complex and incubated for $10 \mathrm{~min}$ at $30^{\circ} \mathrm{C}$ to allow dissociation of the protein from the complex. Ten microliters of each protein sample (one third of the total sample) were analyzed by SDS-PAGE electrophoresis and Western blotting.

\section{ACKNOWLEDGMENTS}

We thank Dr. N. Kedersha for providing antibodies against TIA proteins and TIA expression plasmid, Dr. D. Helfman for the antibody to PTB, Dr. Dreyfuss for the antibody to hnRNP A1, and Dr. H. Lou for PTB expression plasmids and siRNA. We also thank Michael C. Payne for technical assistance with the in vivo injections. This work was supported by NIH grant RO1 HL-66171.

Received September 3, 2004; accepted August 9, 2005.

\section{REFERENCES}

Babij, P. and Periasamy, M. 1989. Myosin heavy chain isoform diversity in smooth muscle is produced by differential RNA processing. J. Mol. Biol. 210: 673-679.

Beck, A.R., Medley, Q.G., O’Brien, S., Anderson, P., and Streuli, M. 1996. Structure, tissue distribution and genomic organization of the murine RRM-type RNA binding proteins TIA-1 and TIAR. Nucleic Acids Res. 24: 3829-3835.

Black, D.L. 2000. Protein diversity from alternative splicing: A challenge for bioinformatics and post-genome biology. Cell 103: 367370 . 
Buerstedde, J.M., Reynaud, C.A., Humphries, E.H., Olson, W., Ewert, D.L., and Weill, J.C. 1990. Light chain gene conversion continues at high rate in an ALV-induced cell line. EMBO J. 9: 921-927.

Charlet, B., Logan, P., Singh, G., and Cooper, T.A. 2002. Dynamic antagonism between ETR-3 and PTB regulates cell type-specific alternative splicing. Mol. Cell 9: 649-658.

Dirksen, W.P., Vladic, F., and Fisher, S.A. 2000. A myosin phosphatase targeting subunit isoform transition defines a smooth muscle developmental phenotypic switch. Am. J. Physiol. Cell. Physiol. 278: C589-C600.

Dirksen, W.P., Mohamed, S.A., and Fisher, S.A. 2003. Splicing of a myosin phosphatase targeting subunit 1 alternative exon is regulated by intronic cis-elements and a novel bipartite exonic enhancer/silencer element. J. Biol. Chem. 278: 9722-9732.

Elbashir, S.M., Harborth, J., Weber, K., and Tuschl, T. 2002. Analysis of gene function in somatic mammalian cells using small interfering RNAs. Methods 26: 199-213.

Fisher, S.A., Ikebe, M., and Brozovich, F. 1997. Endothelin-1 alters the contractile phenotype of cultured embryonic smooth muscle cells. Circ. Res. 80: 885-893.

Forch, P., Puig, O., Kedersha, N., Martinez, C., Granneman, S., Seraphin, B., Anderson, P., and Valcarcel, J. 2000. The apoptosispromoting factor TIA-1 is a regulator of alternative pre-mRNA splicing. Mol. Cell 6: 1089-1098.

Gatto-Konczak, F., Bourgeois, C.F., Le Guiner, C., Kister, L., Gesnel, M.C., Stevenin, J., and Breathnach, R. 2000. The RNA-binding protein TIA-1 is a novel mammalian splicing regulator acting through intron sequences adjacent to a $5^{\prime}$ splice site. Mol. Cell Biol. 20: 6287-6299.

Gooding, C., Roberts, G.C., and Smith, C.W. 1998. Role of an inhibitory pyrimidine element and polypyrimidine tract binding protein in repression of a regulated alpha-tropomyosin exon 10. RNA 4: 85-100.

Graham, F.L., Smiley, J., Russell, W.C., and Nairn, R. 1977. Characteristics of a human cell line transformed by DNA from human adenovirus type 5. J Gen. Virol. 36: 59-74.

Gromak, N., Matlin, A.J., Cooper, T.A., and Smith, C.W. 2003 a. Antagonistic regulation of $\alpha$-actinin alternative splicing by CELF proteins and polypyrimidine tract binding protein. RNA 9: 443456.

Gromak, N., Rideau, A., Southby, J., Scadden, A.D., Gooding, C., Huttelmaier, S., Singer, R.H., and Smith, C.W. 2003b. The PTB interacting protein raver1 regulates $\alpha$-tropomyosin alternative splicing. EMBO J. 22: 6356-6364.

Grossman, J.S., Meyer, M.I., Wang, Y.C., Mulligan, G.J., Kobayashi, R., and Helfman, D.M. 1998. The use of antibodies to the polypyrimidine tract binding protein (PTB) to analyze the protein components that assemble on alternatively spliced pre-mRNAs that use distant branch points. RNA 4: 613-625.

Helper, D.J., Lash, J.A., and Hathaway, D.R. 1988. Distribution of isoelectric variants of the 17,000-dalton myosin light chain in mammalian smooth muscle. J. Biol. Chem. 263: 15748-15753.

Ito, M., Nakano, T., Erdodi, F., and Hartshorne, D.J. 2004. Myosin phosphatase: Structure, regulation and function. Mol. Cell Biochem. 259: 197-209.

Johnson, D., Cohen, P., Chen, M.X., Chen, Y.H., and Cohen, P.T. 1997. Identification of the regions on the M110 subunit of protein phosphatase $1 \mathrm{M}$ that interact with the M21 subunit and with myosin. Eur. J. Biochem. 244: 931-939.

Kedersha, N.L., Gupta, M., Li, W., Miller, I., and Anderson, P. 1999. RNA-binding proteins TIA-1 and TIAR link the phosphorylation of eIF-2 $\alpha$ to the assembly of mammalian stress granules. J. Cell. Biol. 147: 1431-1442.

Kedersha, N., Cho, M.R., Li, W., Yacono, P.W., Chen, S., Gilks, N., Golan, D.E., and Anderson, P. 2000. Dynamic shuttling of TIA-1 accompanies the recruitment of mRNA to mammalian stress granules. J. Cell. Biol. 151: 1257-1268.

Kelley, C.A., Takahashi, M., Yu, J.H., and Adelstein, R.S. 1993. An insert of seven amino acids confers functional differences between smooth muscle myosins from the intestines and vasculature. J. Biol. Chem. 268: 12848-12854.

Khatri, J.J., Joyce, K.M., Brozovich, F.V., and Fisher, S.A. 2001. Role of myosin phosphatase isoforms in cGMP-mediated smooth muscle relaxation. J. Biol. Chem. 276: 37250-37257.

Kimes, B.W. and Brandt, B.L. 1976. Characterization of two putative smooth muscle cell lines from rat thoracic aorta. Exp. Cell. Res. 98: 349-366.

Ladd, A.N. and Cooper, T.A. 2002. Finding signals that regulate alternative splicing in the post-genomic era. Genome Biol. 3: reviews0008.

Ladd, A.N., Charlet, B., and Cooper, T.A. 2001. The CELF family of RNA binding proteins is implicated in cell-specific and developmentally regulated alternative splicing. Mol. Cell. Biol. 21: 12851296.

Le Guiner, C., Gesnel, M.C., and Breathnach, R. 2003. TIA-1 or TIAR is required for DT40 cell viability. J. Biol. Chem. 278: 10465-10476.

Lee, K.A., Bindereif, A., and Green, M.R. 1988. A small-scale procedure for preparation of nuclear extracts that support efficient transcription and pre-mRNA splicing. Gene Anal. Tech. 5: 22-31.

Lou, H., Helfman, D.M., Gagel, R.F., and Berget, S.M. 1999. Polypyrimidine tract-binding protein positively regulates inclusion of an alternative $3^{\prime}$-terminal exon. Mol. Cell Biol. 19: 78-85.

McCutcheon, I.E., Hentschel, S.J., Fuller, G.N., Jin, W., and Cote, G.J. 2004. Expression of the splicing regulator polypyrimidine tractbinding protein in normal and neoplastic brain. Neuro-oncol. 6: 914.

Modrek, B. and Lee, C. 2002. A genomic view of alternative splicing. Nat. Genet. 30: 13-19.

Nabeshima, Y., Nabeshima, Y., Nonomura, Y., and Fujii-Kuriyama, Y. 1987. Nonmuscle and smooth muscle myosin light chain mRNAs are generated from a single gene by the tissue-specific alternative RNA splicing. J. Biol. Chem. 262: 10608-10612.

Ogut, O. and Brozovich, F.V. 2000. Determinants of the contractile properties in the embryonic chicken gizzard and aorta. Am. J. Physiol. Cell. Physiol. 279: C1722-C1732.

Owens, G.K., Kumar, M.S., and Wamhoff, B.R. 2004. Molecular regulation of vascular smooth muscle cell differentiation in development and disease. Physiol. Rev. 84: 767-801.

Payne, M.C., Zhang, H.Y., Shirasawa, Y., Koga, Y., Ikebe, M., Benoit, J.N., and Fisher, S.A. 2004. Dynamic changes in expression of myosin phosphatase in a model of portal hypertension. Am. J. Physiol. Heart Circ. Physiol. 286: H1801-H1810.

Payne, M.C., Joyce, K.M., Prosdocimo, D., Koga, Y., Ikebe, M., and Fisher, S.A. 2005. Myosin phosphatase isoform switching in vascular smooth muscle development. J. Mol. Cell. Cardiol. (in press).

Perez, I., Lin, C.H., McAfee, J.G., and Patton, J.G. 1997. Mutation of PTB binding sites causes misregulation of alternative $3^{\prime}$ splice site selection in vivo. RNA 3: 764 .

Piecyk, M., Wax, S., Beck, A.R., Kedersha, N., Gupta, M., Maritim, B., Chen, S., Gueydan, C., Kruys, V., Streuli, M., et al. 2000. TIA-1 is a translational silencer that selectively regulates the expression of TNF- $\alpha$. EMBO J 19: 4154-4163.

Polydorides, A.D., Okano, H.J., Yang, Y.Y., Stefani, G., and Darnell, R.B. 2000. A brain-enriched polypyrimidine tract-binding protein antagonizes the ability of Nova to regulate neuron-specific alternative splicing. Proc. Natl. Acad. Sci. 97: 6350-6355.

Rahman, L., Bliskovski, V., Reinhold, W., and Zajac-Kaye, M. 2002. Alternative splicing of brain-specific PTB defines a tissue-specific isoform pattern that predicts distinct functional roles. Genomics 80: $245-249$.

Samaha, F.F., Ip, H.S., Morrisey, E.E., Seltzer, J., Tang, Z., Solway, J., and Parmacek, M.S. 1996. Developmental pattern of expression and genomic organization of the calponin-h1 gene: A contractile smooth muscle cell marker. J. Biol. Chem. 271: 395-403.

Schmucker, D., Clemens, J.C., Shu, H., Worby, C.A., Xiao, J., Muda, M., Dixon, J.E., and Zipursky, S.L. 2000. Drosophila Dscam is an axon guidance receptor exhibiting extraordinary molecular diversity. Cell 101: 671-684. 
Shen, H., Kan, J.L, Ghigna, C., Biamonti, G., and Green, M.R. 2004. A single polypyrimidine tract binding protein (PTB) binding site mediates splicing inhibition at mouse IgM exons M1 and M2. RNA 10: 787-794.

Shimizu, H., Ito, M., Miyahara, M., Ichikawa, K., Okubo, S., Konishi, T., Naka, M., Tanaka, T., Hirano, K., Hartshorne, D.J., et al. 1994. Characterization of the myosin-binding subunit of smooth muscle myosin phosphatase. J. Biol. Chem. 269: 30407-30411.

Shukla, S., Dirksen, W.P., Joyce, K.M., Guiner-Blanvillain, C., Breathnach, R., and Fisher, S.A. 2004. TIA proteins are necessary but not sufficient for the tissue-specific splicing of the myosin phosphatase targeting subunit 1. J. Biol. Chem. 279: 13668-13676.

Smith, C.W. and Valcarcel, J. 2000. Alternative pre-mRNA splicing: The logic of combinatorial control. Trends Biochem. Sci. 25: 381-388.

Smith, R.L., Traul, D.L., Schaack, J., Clayton, G.H., Staley, K.J., and Wilcox, C.L. 2000. Characterization of promoter function and celltype-specific expression from viral vectors in the nervous system. J. Virol. 74: 11254-11261.

Sobue, K., Hayashi, K., and Nishida, W. 1999. Expressional regulation of smooth muscle cell-specific genes in association with phenotypic modulation. Mol. Cell Biochem. 190: 105-118.

Somlyo, A.V. and Somlyo, A.P. 1968. Electromechanical and pharmacomechanical coupling in vascular smooth muscle. J. Pharmacol. Exp. Ther. 159: 129-145.

Taupin, J.L., Tian, Q., Kedersha, N., Robertson, M., and Anderson, P. 1995. The RNA-binding protein TIAR is translocated from the nucleus to the cytoplasm during Fas-mediated apoptotic cell death. Proc. Natl. Acad. Sci. 92: 1629-1633.
Tian, Q., Streuli, M., Saito, H., Schlossman, S.F., and Anderson, P. 1991. A polyadenylate binding protein localized to the granules of cytolytic lymphocytes induces DNA fragmentation in target cells. Cell 67: 629-639.

Ueki, N., Sobue, K., Kanda, K., Hada, T., and Higashino, K. 1987. Expression of high and low molecular weight caldesmons during phenotypic modulation of smooth muscle cells. Proc. Natl. Acad. Sci. 84: 9049-9053.

Valcarcel, J. and Gebauer, F. 1997. Post-transcriptional regulation: The dawn of PTB. Curr. Biol. 7: R705-R708.

Wagner, E.J. and Garcia-Blanco, M.A. 2001. Polypyrimidine tract binding protein antagonizes exon definition. Mol. Cell. Biol. 21: 3281.

. 2002. RNAi-mediated PTB depletion leads to enhanced exon definition. Mol. Cell 10: 943-949.

Wieczorek, D.F., Smith, C.W., and Nadal-Ginard, B. 1988. The rat $\alpha$ tropomyosin gene generates a minimum of six different mRNAs coding for striated, smooth, and nonmuscle isoforms by alternative splicing. Mol. Cell Biol. 8: 679-694.

Wollerton, M.C., Gooding, C., Robinson, F., Brown, E.C., Jackson, R.J., and Smith, C.W. 2001. Differential alternative splicing activity of isoforms of polypyrimidine tract binding protein (PTB). RNA 7: 819-832.

Zuccato, E., Buratti, E., Stuani, C., Baralle, F.E., and Pagani, F. 2004. An intronic polypyrimidine-rich element downstream of the donor site modulates cystic fibrosis transmembrane conductance regulator exon 9 alternative splicing. J. Biol. Chem. 279: 1698016988. 

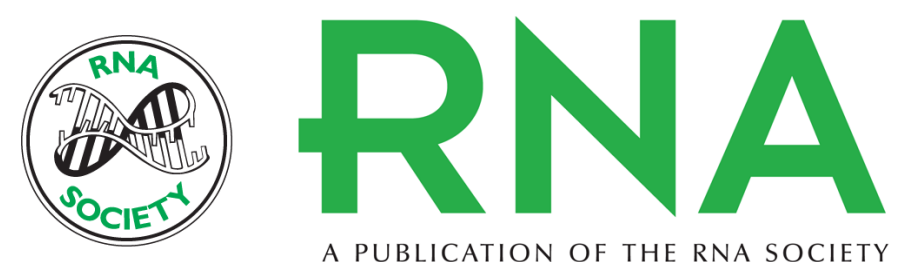

A PUBLICATION OF THE RNA SOCIETY

\section{Competition of PTB with TIA proteins for binding to a U-rich cis -element determines tissue-specific splicing of the myosin phosphatase targeting subunit 1}

SUPRIYA SHUKLA, FABIENNE DEL GATTO-KONCZAK, RICHARD BREATHNACH, et al.

RNA 2005 11: 1725-1736

References

This article cites 57 articles, 31 of which can be accessed free at:

http://rnajournal.cshlp.org/content/11/11/1725.full.html\#ref-list-1

License

Email Alerting Service
Receive free email alerts when new articles cite this article - sign up in the box at the top right corner of the article or click here. 